\title{
Performance Measure of CI Engine by Varyingblends with Different Proportions and Parameters
}

\author{
T.Kathiravan, R. Karthikeyan, J.Murugesan, N. Narendran
}

\begin{abstract}
Many researchers have been working on alternative fuels and it blends in order to enhance the performance of automobiles. There are number of alternative fuel blends have been tested on automobile engines and their performances have been analyzed. In this present work, Methyl Ester from Waste cooking oil to be prepared and going to blend with Diesel with different ratios, is an alternative fuel. The experiment is going to be conducted on the air cooled four stroke Diesel engine using these blends with different proportions and nozzle injection pressures, finally its performance characteristics to be analyzed.
\end{abstract}

Keywords:Methyl Ester, Waste cooking oil, Alternate fuels.

\section{INTRODUCTION}

The dominant source of transportation in modern world is Diesel engine. But due to shortage of fuel, we may not be able to avail it for long time. Similarly, reduction of fuel consumption also focused in automobile industries. Various researches are practiced to overcome the above challenges.

The current situation of petroleum and the depletion of fossil fuels and degradation of our environment due to the combustion of fuels leads to urgency interest in finding alternative to fossil fuel which is none other than Bio-Diesel which are eco-friendly. Thermodynamic performance test conducted on engine also favors for the use of alternative fuel in Diesel engines.Various reports indicate that the use of Bio-Diesel on Diesel engines have shown substantial reduction in the emission of $\mathrm{SO} 2, \mathrm{CO} 2, \mathrm{NOx}$ content which are all the major responsibilities for environment degradation. Pure plant oils are completely harmless to our environment especially for ground water table and ground water as a general rule that the blend of Bio-Fuel and petroleum Diesel should also be treated as petroleum Diesel. Fuel Injection:

Fuel injection is atomizing the fuel through the nozzle to the pressure of 200 bar using fuel nozzles to the combustion chamber of the engine cylinder

This injection process is making of droplets of fuel to support the complete combustion. Viscosity is one of the physical characteristics of fluidwhich is the resistance offered by the fluid layers for the fluid flow.

Revised Manuscript Received on November 19, 2019

Kathiravan, Department ofMechanical Engineering, PSNACET, Dindigul

R.Karthikeyan, Department ofMechanical Engineering, PSNACET, Dindigul

J.Murugesan, Department ofMechanical Engineering, PSNACET, Dindigul

N.Narendran, Department of Chemistry, PSNACET,Dindigul
Atomization rates of the fuel is dropped while increasing the density. Surface tension or the tendency of the fuel to adhere to itself at the fuel- air interface, affects the tendency of the fuel to forms drops at the jet-air interface.

\section{EXPERIMENTATION}

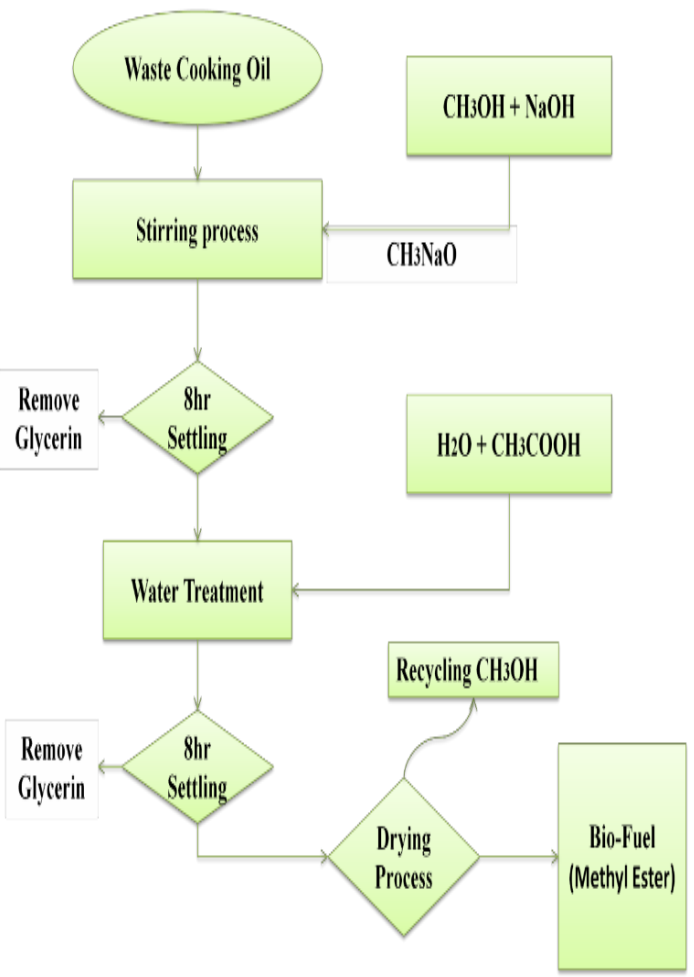

Fig2.1 Process of Bio-Fuel flow chart

III. PREPARATION PROCESS OF BIO-FUEL

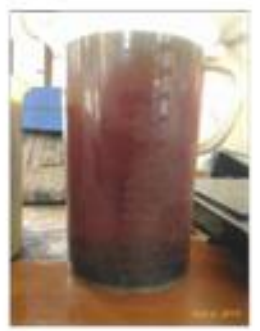

1) Settled oil and glycerin

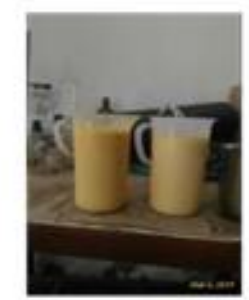

VI) Settling proces: 

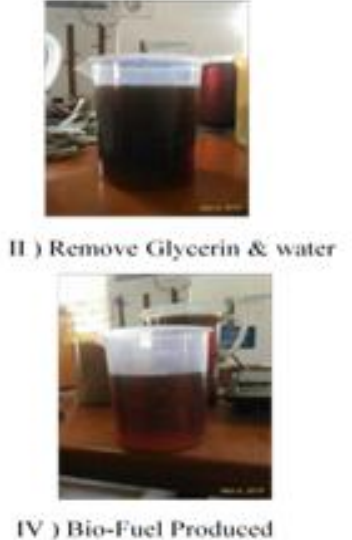
IV ) Bio-Fuel Produce
(Methyl Ester)

Fig3.1 Process of Bio-Fuel

Engine Specifications

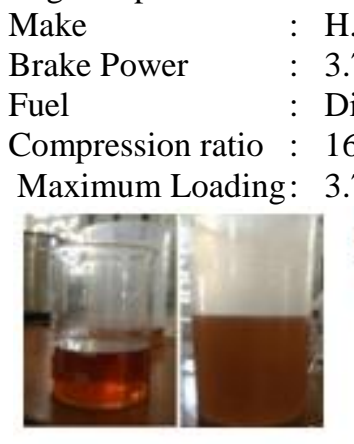

H.T.C. Diesel Engine

$3.7 \mathrm{~kW}$ or $5 \mathrm{hp} @ 1500 \mathrm{rpm}$

$\begin{array}{ll}\text { Fuel } & : \text { Diesel } \\ \text { Compression ratio : } 16.1\end{array}$

Maximum Loading: $3.7 \mathrm{~kW}$

\section{Blendratio $1: 9$}

Bio-Fuel $10 \%=$ Diesel $90 \%$

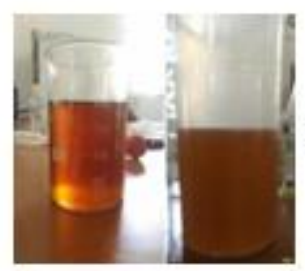

Bio-Fuel $20 \%=$ Diesel $80 \%$

Blend ratio $2: 8$

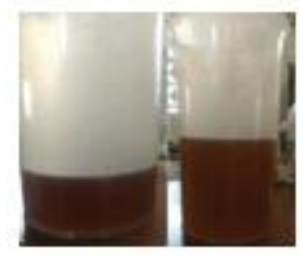

Blendratio $3: 7$

Bio-Fuel $30 \%=$ Diesel $70 \%$

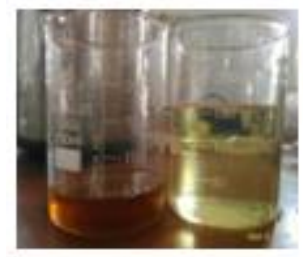

Bio-Fuel $40 \%=$ Diesel $60 \%$

Blendratio $4: 6$

Fig3.2 Process of Bio-Fuel

\section{PROCESS OF BIO-DIESEL PRODUCTION}

1. Filter the oil to remove solid particles. Oil is warmed up little bit to get it to run freely, $35^{\circ} \mathrm{C}$ is enough. 2 . To avoid the soap formation (Saponification) oil seed is heated to $120^{\circ} \mathrm{C}$ so that water is evaporated completely. 3. Preparing methanol and Sodium hydroxide mixture: First make sure that vessels are dry. Start by mixing exact quantity (3g) of Sodium hydroxide and $(200 \mathrm{ml})$ methanol for $1000 \mathrm{ml}$ of oil. 4 .

Separation of fatty content: Mix the precise amount of methanol and Sodium hydroxide followed by constant stirring and then allowed to cool. Then extract the oil for further process. 5. Preparing meth oxide: First make sure that vessels used are dry. The mixing of the precise quantity $(3 \mathrm{~g})$ of Sodium hydroxide and Methanol $(200 \mathrm{ml})$ and Stirring until the cent percent of Sodium hydroxide is dissolved. Once the Sodium methoxide is made and add $1 \mathrm{~kg}$ of oil. Make sure all your weight and volumes are precise. The quantity of $\mathrm{NaOH}$ is concise such that the reaction is simpler. It is mandate that the right volume of $\mathrm{NaOH}$ do boost up the reaction and to escape from some unreacted oil will be mixed with Bio-Diesel and glycerin. 6. Heating and mixing: Pre-heat oil to $50^{\circ} \mathrm{C}$ to $60^{\circ} \mathrm{C}$. Add Sodium meth oxide to the oil while stirring; stir the mixture for 50 minutes.. The $\mathrm{CH}_{3} \mathrm{OH}$ is then the caps off the ester chains and $\mathrm{OH}$ from the $\mathrm{NaOH}$ stabilizes the glycerin. Measure 1 litre of distilled water and add acetic acid $(0.3 \mathrm{ml})$ and them mixed with the solution and allow it to settle. 7. Allow the solution forsettling and cooling processes for 8 hours. The methyl esters (Bio-Diesel) are in the top of the solution the high denser glycerin is congealed on the bottom of the container. The Bio-Diesel is take off carefully from the final solution. This can be done by draining the unwanted reactants out of the bottom of the container through the vicinity hose.

8. The suspension of Bio-Diesel may also have some soapy residues. These are the result of $\mathrm{k}$ ions from the Sodium methoxide reaction with water was suspended in the oil. If the reaction produces more than the usual amount of soap, this happens when $\mathrm{NaOH}$ comes in contact with water before it has a chance to react with the oil.


Fig4.1 Process of Bio-Fuel

\section{Formula used}

1. Brake Power BP: $(2 \pi N W g r e) /(60 \times 1000) \mathrm{kW}$

2. Total Fuel Consumption TFC $=10 / \mathrm{t} \times \gamma \times 3600 / 1000 \mathrm{~kg}$ / hr.

3. Frictional Power IP $=\mathrm{BP}+\mathrm{FP} \mathrm{kW}$

4..Actual mass of air $=\mathrm{C}_{\mathrm{d}} \times \rho_{\mathrm{a}} \times \mathrm{A}\left(2 \mathrm{gh}_{\mathrm{a}}\right)^{1 / 2} \times 3600 \mathrm{Kg} / \mathrm{hr}$.

5. Theoretical mass of air $\mathrm{Mt}=\left(\pi \mathrm{d}^{2} \mathrm{LN} / 8\right) \rho_{\mathrm{a}} \times 60 \mathrm{~kg} / \mathrm{hr}$.

6. Air fuel ratio $=$ Actual air intake $/ \mathrm{TFC}$

7. Mechanical efficiency $\eta_{\text {mech }}=$ BP / IP

8. Brake thermal efficiency $\eta_{\mathrm{bth}}=\mathrm{BP} /$ Fuel Power

9. Indicated thermal efficiency $\eta_{\text {ith }}=$ IP / Fuel power

10. Brake Mean Effective Pressure

$\mathrm{BMEP}=(120 \mathrm{BP} / \mathrm{LAN}) \mathrm{kN} / \mathrm{m}^{2}$

11. Indicated Mean Effective Pressure

$\mathrm{IMEP}=(120 \mathrm{BP} / \mathrm{LAN}) \mathrm{kN} / \mathrm{m}^{2}$

Total Number of Observation:

1 Nozzle $\times 1$ FIP $\times 4$ Blend $\times 1$ loads $=4$ 


\section{RESULT AND DISCUSSION}

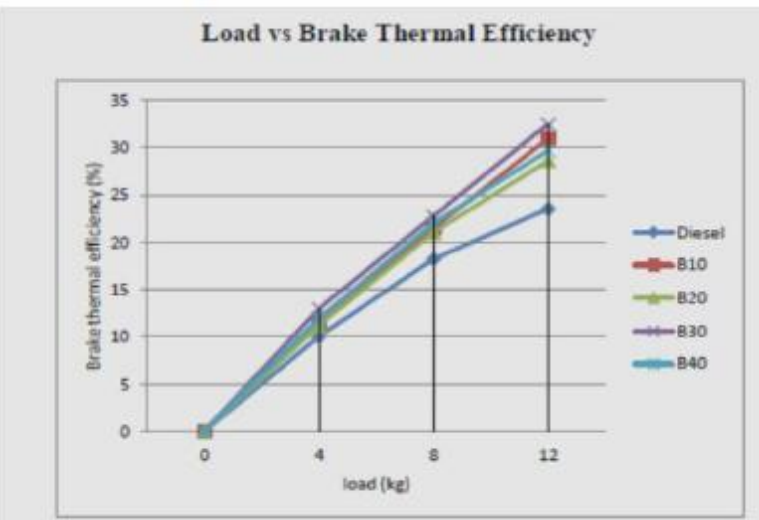

Fig 5.1Variation of Brake Thermal Efficiency (FIP 140psi)

Thermal efficiency is the ratio between useful output of a device and the input energy. The relation between output energy(Shaft Power) and input energy (Fuel).The variation of brake thermal efficiency (BTE) for various Injection Pressure and for different blends is given in Figure.

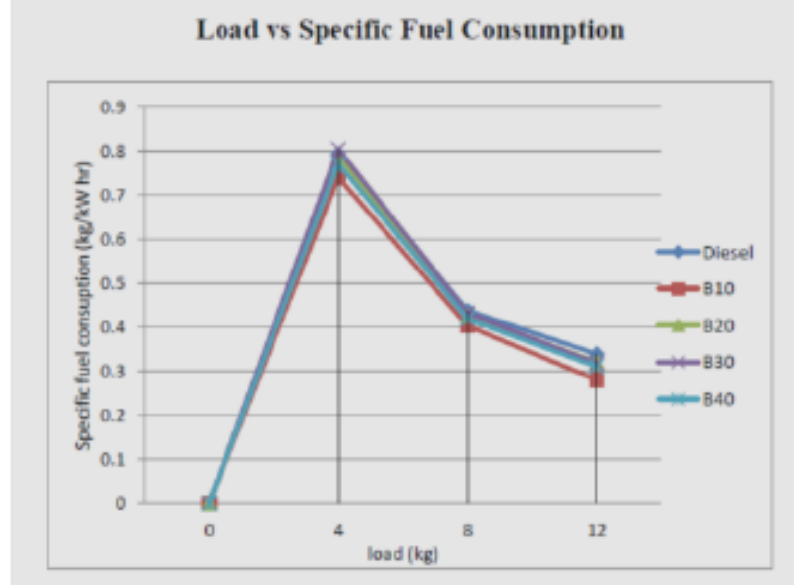

Fig 5.2 Variation of Specific Fuel Consumption (FIP 140psi)

SFC is one of the performance parameter which emphasis the rated power output for the given amount of fuel consumption. Higher SFC means higher fuel consumption (i.e. less power per unit of fuel consumed). Lower SFC means higher power per unit of fuel consumed. It is the weight of fuel consumed per kWhr of power produced. As the injection pressure increases SFC decreases producing higher power per unit of fuel consumed.

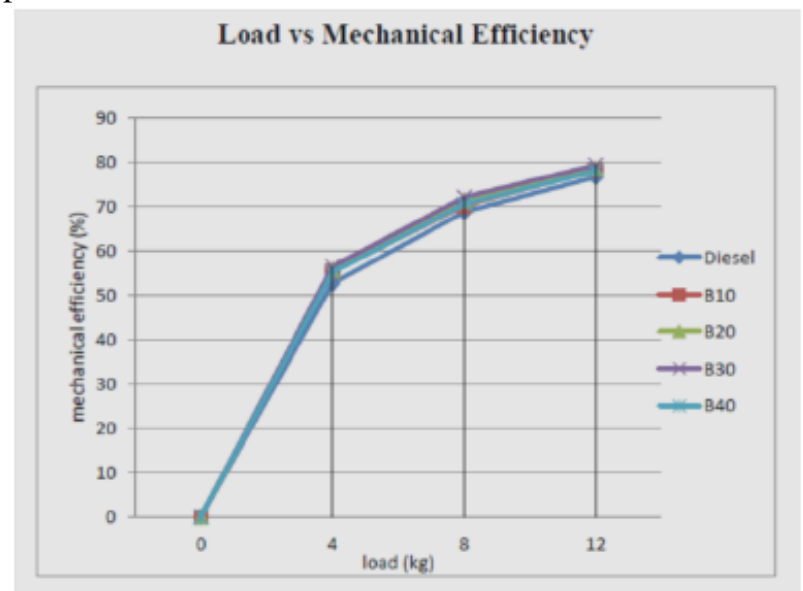

Fig 5.3Variation of Mechanical Efficiency (FIP 140psi) Mechanical efficiency $\left(\eta_{\text {mech }}\right)$ is the ratio of Brake power to
Indicated power. The variations of Mechanical efficiency for various Compression Ratio and different blends are shown in figure.

Thermal efficiency is the ratio between useful output of a device and the input energy. Indicated efficiency is total power output by burning the fuel during every cycle. The variation of indicated thermal efficiency has been obtained based on different Injection Pressure and for different blends are given in Figure.

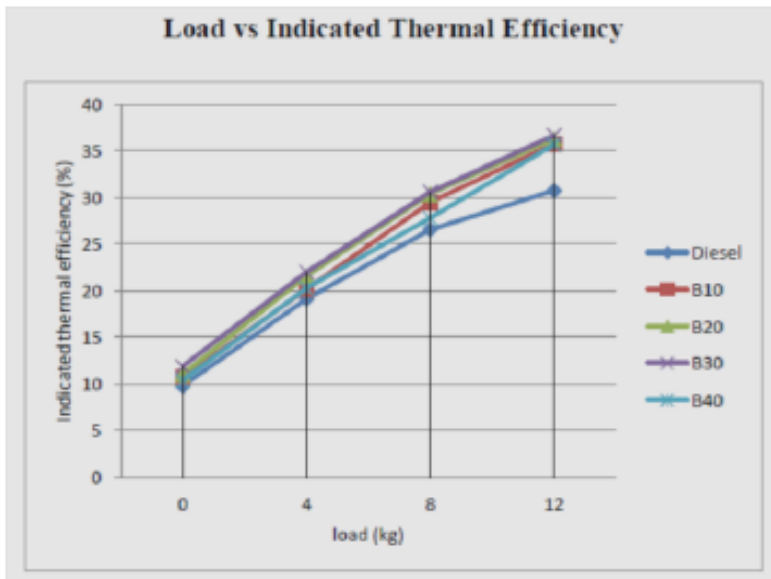

Fig 5.4Variation of Indicated Thermal Efficiency (FIP 140psi)

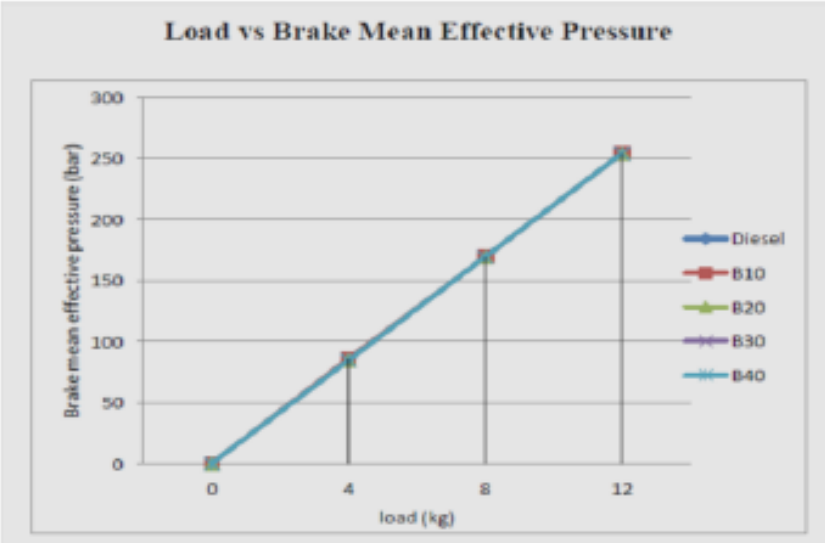

Fig 5.5 Variation of Brake Mean Effective Pressure (FIP 140psi)

The variation of volumetric efficiency for various Compression Ratio and for different blends is shown in figure.

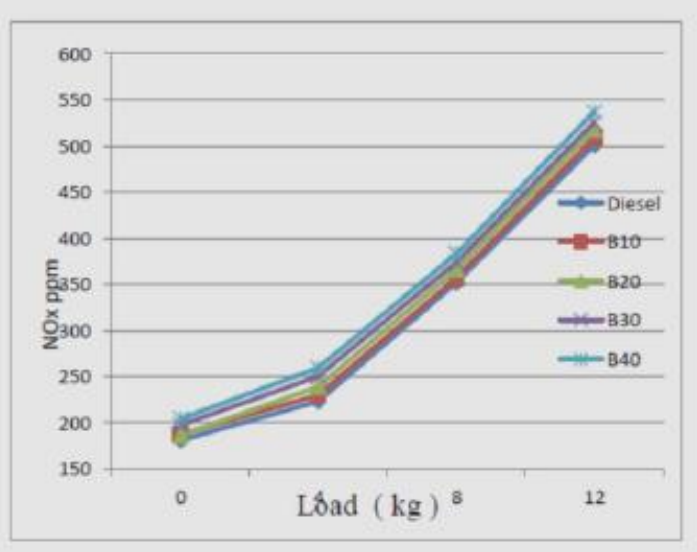

Fig 5.6 Variation of Nitrogen Oxide (FIP 140psi)

Published By:

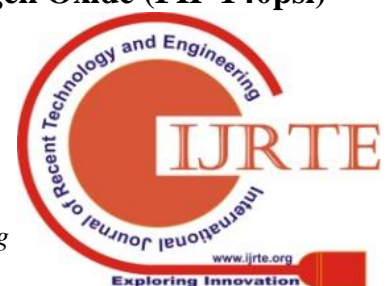




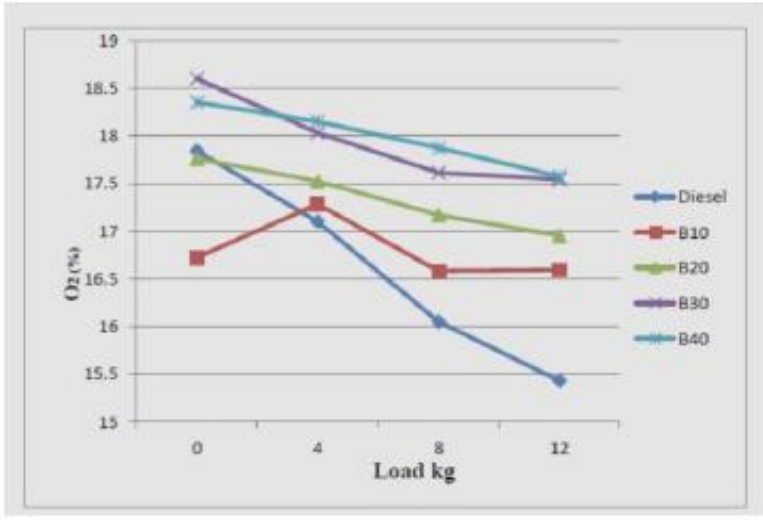

Fig 5.7 Variation of Oxygen (FIP 140psi)

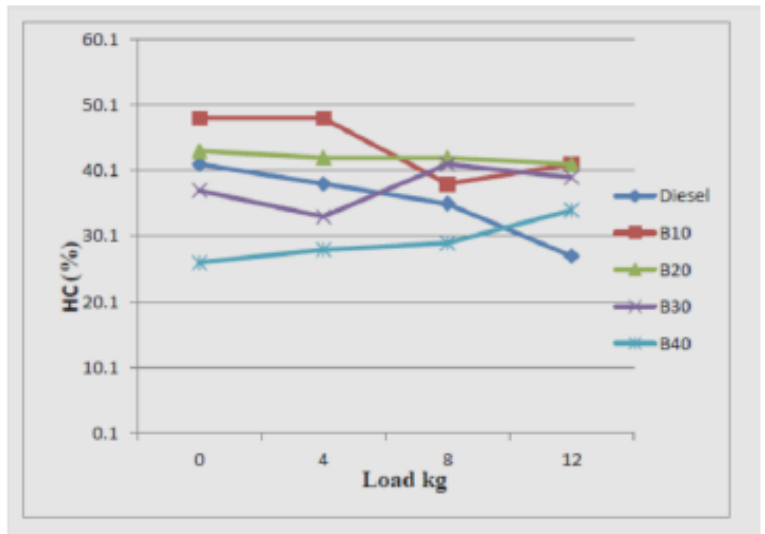

Fig 5.8 Variation of Hydrogen and carbon (FIP 140psi)

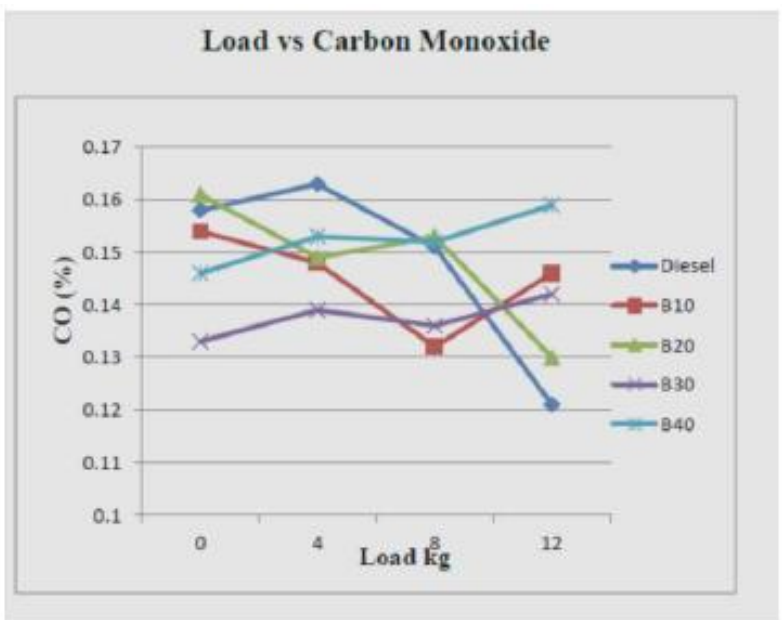

Fig 5.9Variation of Carbon Monoxide (FIP 140psi)

\section{CONCLUSION:}

It is observed that the performance parameters like Mechanical, brake thermal and indicated thermal efficiencies were enhanced by $2.7 \%, 5.09 \%$ and $5.93 \%$ respectively at the injection pressure of 140 psi. From the comparison, B30 is better than other blends at injection pressure 140 psi because it shows higher efficiencies than others. More over this blend has also shown better emission control up to $30 \%$.

\section{REFERENCES}

1. Yasin NHM et al. (2011) "Microalgae as a sustainable energy source for Bio-Diesel production: a review". Renew Sustain Energy Rev, Vol. 15 , pp. 584-593.
2. Hebbal, O. (2015) "Process optimization for Bio-Diesel production from simarouba, mahua, and waste cooking oils". International Journal of Green Energy, Vol. 12, No. 4, pp. 424-430.

3. Palvannan, $\mathrm{V}$ et al. (2012) "Experimental Investigation of Performance and Emission of Jatropha Esters and Cashew Nut Shell Liquid in DI Compression Ignition Engine". Automation and Autonomous System, Vol. 4, No. 7, pp. 301-310.

4. Pushparaj, T et al (2012) "Influence of CNSL Bio-Diesel with ethanol additive on Diesel engine performance and exhaust emission". International journal of mechanical engineering and technology, Vol. 3, No. 2, pp. 665-674.

5. Radhakrrishnan, S.,Thamodharan, C., \&Senthilnathan, N. (2014) "Evaluating Performance and Emission Characteristics Of CI Engine Run By Cashew Nut Shell Liquid (CNSL) As a Fuel". International journal of scientific \&technologyresearch, Vol. 3, No. 4, pp. 13-18.

6. Rajasekar E, et al (2014) "Review of combustion characteristics of CI engines fueled with biodiesel". Renew Sustain Energy Rev, Vol. 35, pp. 390- 399.

\section{AUTHORS PROFILE}

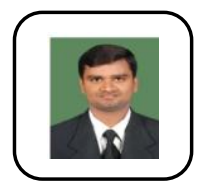

Mr.T.Kathiravan, Assistant Professor in Department of Mechanical Engineering, PSNA College of Engineering and Technology, Dindigul, TamilNadu, having 7years of Experience in teaching and 8 years in industry. He has published papers in various journals and internationalconferences. His area of expertise is Heat transfer.

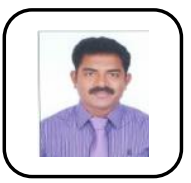

Mr.R. Karthikeyan, Assistant Professor in Departmentof Mechanical Engineering,PSNA College of Engineering and Technology, Dindigul, TamilNadu, having 8 years of Experience in teaching and 3 years in industry. He has published papers in various journals and international Mechatronics. conferences. His area of expertise is Automation and



Mr.J.Murugesan, Assistant Professor in Departmentof Mechanical Engineering, PSNA College of Engineering and Technology, Dindigul, TamilNadu, having 7 years of Teaching Experience and $\mathrm{He}$ has published papers in various journals and international conferences. His area of expertise is design and optimization.

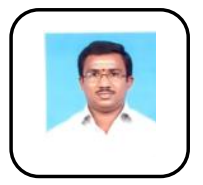

Mr.N,Narendran, Assistant Professor in Department of Chemistry, PSNA College of Engineering and Technology, Dindigul, TamilNadu, having 15 years of Teaching Experience and He has published papers in various journals and international conferences. His area of expertise is organic and environmental chemistry 